\title{
ANALYSIS OF RETURN ON INVESTMENT IN SOME NIGER-DELTA OIL FIELD PROJECTS: USING THE VARIANCE-GAMMA PROCESS
}

\section{CHISARA PEACE OGBOGBO}

\author{
(Received 5 December 2018; Revision Accepted 21 January 2019)
}

\begin{abstract}
Oil field development projects face market risks, largely because the parameter of key importance, the oil price, fluctuates rapidly over time. The decision to invest or not in an oil field project is therefore very challenging, because information concerning the field is often scarce. Neither the future production, nor sales prices are known with certainly. Constraints on production level also exist, in addition to OPEC quota, which is used in this work as proxy for other production limitations. The price process that best describes the fluctuations in oil price is expected to yield better analysis with respect to expected returns (viability of the project). The Variance Gamma process which is a subordinated Lévy process effectively captures jumps in a process. Thus, Variance Gamma process and a mean reverting process are considered in the analysis. The expected revenue was found to be higher, when the variance Gamma process is used as the model for oil price. This indicates that the variance Gamma process performs better than the Ornstein-Uhlenbeck process as a model for oil price. It therefore provides a good basis for price forecasting, and optimality of investment decision.
\end{abstract}

KEYWORDS: Variance Gamma Process, Mean Reverting Process, Parameters, Niger-Delta Oil Field Projects, Expected Return, OPEC constraint.

\section{INTRODUCTION}

This paper discusses findings that emerged while seeking an answer to a different question. The emphasis here is not exactly, on optimality of decision, but on analysis of revenue accruing (to an investor) with respect to the process describing fluctuations in oil price. Traditional tools such as net present value (NPV), discount factor (DCF), had been used generally in analysis involving expected returns on investment, to provide information about (viability of) a project. In these static models, calculations are done with fixed oil price premise. This can grossly over estimate projected gains or severely undermine a project's viability. The case study here is some Niger Delta fields. The oil price data is calibrated to obtain parameters to fit the process. A computational attempt is made at obtaining maximum return, using two different price processes: - a mean reverting process, and a subordinated Levy processes, the Variance Gamma, (VG) process. This is done in the face of Organization of petroleum exporting countries, OPEC constraints, which is a proxy for other production limitations. This is because production is not without an upper bound. Analysis is done with respect to various parameters of these processes.

Mean reverting processes are processes with the tendency to move away from their initial positions but return to a long -term mean (price) in the long run. The simplest mean reverting process is the Ornstein and Uhlenbeck $(\mathrm{O}-\mathrm{U})$ process. The process is stationary, Gaussian, and Markovian. The O-U process though a
Gaussian process is different from the Weiner process by the drift term. If the current value of the process is less than the (long-term) mean, the drift will be positive; if the current value of the process is greater than the (long-term) mean, the drift will be negative. In other words, the mean acts as an equilibrium level for the process. The Weiner process has constant drift.

Mean reverting processes such as the $\mathrm{O}-\mathrm{U}$ process are used in finance to model interest rates, currency exchange rates as well as commodities prices. This recommends the O-U model for the study of crude oil price, (which is characterized by fluctuations) to determine whether the process would capture the type of movement in crude oil price. Black Scholes Model is a Gaussian model used for pricing options. The main shortcoming of the Black Scholes model is the assumption that the volatility in the price of the underlying security is constant. This is responsible for the great incentive to produce other models which can describe the movement in crude oil price. The O-U process is therefore considered, to ascertain if mean reversion is a characteristic exhibited by the crude oil price series. On the other hand, the Variance gamma process is an infinite activity Lévy process, which can model small and frequent large jumps. As a subordinated Levy process, its ability to capture jumps informs its use in the analysis to investigate the presence or not of jumps in crude oil price series. The result of the analysis done in this work is expected to highlight the price process describing crude oil price. The aim of this work is to determine which process leads

Chisara Peace Ogbogbo, Department of Mathematics University of Ghana, Legon. Accra, Ghana. 
to better performance for a field project given constraint on production. Against this backdrop, we use a model which computes expected return on the project for each process, given OPEC production constraint. The price process that best describes the fluctuations in oil price is expected to yield better analysis with respect to expected returns (viability of the project). We compare results from analysis of returns on investment in oil field, using $\mathrm{O}-\mathrm{U}$ process and $\mathrm{VG}$ process.

Data used is data for 13 crude types and fields from some Niger Delta oil field projects. The results are obtained computationally using PYTHON programming language. Parameter estimation for the O-U and VG processes are done using MLE. Codes for these computations are lengthy and can be obtained from author, through the given contact. The data was obtained from Department of Petroleum Resources (DPR) Victoria Island Lagos, and the Crude Oil Marketing Division (COMD). It was confirmed at National Petroleum Investment Management Services (NAPIMS) Ikoyi Lagos. For the period under study, January 2005 December 2009, two sets of data were collected. Data on price of various crude types, and data on production for 13 fields. The data available are monthly data and not daily data as may be quoted on NYMEX and IPE. (Commodities and futures market). The prices are considered as spot prices and are used by the Federal Government of Nigeria to collect royalty from oil companies drilling on these fields.

First sieving of the comprehensive data procured had to be done, to match crude types with fields from where they are drilled. The Nigerian crude basket is made up of different crude types from various fields. Some price and production columns were blank probably due to intermittent crisis in the Niger Delta during part of the period. Care had to be taken to choose fields and crude types corresponding to prices, that had meaningful data.
The rest of the paper is presented as follows: The second section gives a brief review of work done in oil price modeling. Section 3 presents some important concepts with respect to the processes, calibration of data is also done here. Section 4 presents the model and analysis of results obtained. Conclusion is drawn.

\section{Brief Review of Work on Oil Price Modeling and Useful Information about OPEC Quota}

Crude oil price futures have been studied by Krichene (2006), (2008). He modeled oil futures price returns as a Lévy process, in particular as a Variance Gamma process. He assumed that oil futures price returns, followed a Lévy process with a variance-gamma (VG) distribution. He defined $\log$ price return as $x_{t}=\Delta \log S_{t}=$ $\mu+X_{t}-X_{t-1}$

Where $X_{t}$, is a variance Gamma process, and crude oil price $S_{t}$ is modeled as

$$
\mathrm{S}_{\mathrm{t}}=\mathrm{S}_{0} \exp \left[\mu \mathrm{t}+\mathrm{X}_{\mathrm{t}}\right]
$$

He used data on daily oil futures prices January 2, 2002July 7,2006 , to estimate the parameters of the VG process using Empirical characteristic function, ECF. He obtained the following parameters Drift $\mu$, Skewness $\alpha$, Volatility $\sigma$, Variance of VG, $v$. Going by his finding, crude oil price exhibited a high drift coefficient $(\mu)$, also exhibited high volatility $(\sigma)$, frequent and large jumps (determined by $v$ ) and skewness (controlled by $\alpha$ ).

OPEC sets up oil production quota to pursue stability and harmony in the petroleum market, for the benefit of both oil producers and consumers. Production regulation is simply one possible response of OPEC to market conditions: if demand grows, or some producers are producing less oil, OPEC can increase its oil production in order to prevent a sudden rise in prices. It might also reduce its oil production, in response to market conditions.

Table 1: Nigeria: OPEC Quota

\begin{tabular}{|c|c|c|c|c|}
\hline $\begin{array}{l}2005 \\
2009\end{array}$ & 2006 & & 2007 & 2008 \\
\hline $\begin{array}{l}2.4 \mathrm{mbpd} \\
\mathrm{mbpd}\end{array}$ & $3.30 \mathrm{mbpd}$ & $2.2 \mathrm{mbpd}$ & $1.3 \mathrm{mbpd}$ & 1.67 \\
\hline
\end{tabular}

Source: www.oilandenergytrends.com/ger/ger_opec oil and energy trends: A monthly publication of International Energy Statistics and Analysis.

\section{Preliminary Concepts}

\subsection{Mean Reverting process}

Mean reversion is the tendency for the Brownian motion to move away from its initial position but return to a mean (price) in the long run or after some time. The simplest mean reverting process is the OrnsteinUhlenbeck process given in equation (1) below

$$
\begin{aligned}
& \mathrm{dP}_{\mathrm{t}} \\
& =\eta\left(\mathrm{P}_{\mathrm{t}}-\mathrm{a}\right) \mathrm{dt}+\sigma \mathrm{dW}_{\mathrm{t}}
\end{aligned}
$$

Where $\eta$ is speed of reversion. $P_{t}$ is oil price, $t$ is time, $\sigma$ is variance parameter, $a$ is level the price tends to revert to (the mean), $\mathrm{dW}_{\mathrm{t}}$ is increment of a Wiener process.

Note: Smaller $\eta$ implies that price drifts away from its mean, ( $\eta$ is non-negative). Also $\eta=1$ implies oil price reverts surely to the long run mean $\alpha$. This process is driven by a Brownian motion. The main parameters of the $\mathrm{O}-U$ process are the mean $\alpha$ and the volatility $\sigma$.
To obtain the price process, $\mathrm{P}_{\mathrm{t}}$ the stochastic differential equation in (1) is solved using Itô's lemma and for given initial conditions. i.e.

$$
d P_{t}=\eta\left(P_{t}-a\right) d t+\sigma d W_{t} P_{0}=P(0)
$$

to obtain

$$
\mathrm{P}_{\mathrm{t}}=\mathrm{P}_{0} \mathrm{e}^{\mathrm{t}}+\mathrm{a}\left(1-\mathrm{e}^{\mathrm{t}}\right)+\int_{0}^{\mathrm{t}} \mathrm{e}^{\mathrm{t}-\mathrm{s}} \sigma \mathrm{dW}_{\mathrm{s}}
$$

Due to the autoregressive quality, increments or jumps are not independent. The farther away the process has moved from the mean, the stronger the tendency for a movement towards the mean. Thus, the speed of reversion is proportional to the distance between the current position and the equilibrium level. So, the variance grows at first but then stabilizes.

\subsection{The Variance Gamma (VG) process}


A variance-gamma (VG) process is defined as a Brownian motion, BM with drift $\mu$ and volatility $\sigma$ i.e. $\mu \mathrm{t}+\sigma \mathrm{B}_{\mathrm{t}}$, where $\mathrm{B}_{\mathrm{t}}$ is an ordinary Brownian motion, timechanged by a gamma process.

Let $G=\left\{G_{t}, t \geq 0\right\}$ be a gamma process with mean $\alpha>$ 0 and variance $b>0$.

Let $B=\left\{B_{t}, t \geq 0\right\}$, denote a Brownian motion, and let $\sigma>0$ and $\mu \in \mathbb{R}$; then the VG process,

$\mathrm{X}^{(\mathrm{VG})}=\left\{\mathrm{X}_{\mathrm{t}}^{(\mathrm{VG})}, \mathrm{t} \geq 0\right\} \sigma>0, \mathrm{v}>0$ and $\mu$ can be defined as

$$
\mathrm{X}_{\mathrm{t}}^{(\mathrm{VG})}=\mu \mathrm{G}_{\mathrm{t}}+\sigma \mathrm{B}_{\mathrm{G}_{\mathrm{t}}}
$$

Thus, the VG process is obtained on evaluating Brownian motion at a time given by the gamma process. It is also called the Laplace motion, and is a pure jump process. When Brownian motion is time changed by a Gamma process, the Variance Gamma (VG) process is obtained. The VG process has three parameters, namely volatility of the $\mathrm{BM}, \sigma$, variance of the gamma time change, $v$, and drift in the Brownian motion, $\mu$. More generally, for $V G$ process defined as

$\mathrm{X}_{\mathrm{X}}^{\mathrm{VG}}=\theta \mathrm{G}_{\mathrm{t}}+\sigma \mathrm{B}_{\mathrm{G}_{\mathrm{t}}}$

There are four parameters: - drift of $\mathrm{BM}, \mu$, volatility of $\mathrm{BM}, \sigma$, volatility of time change, $v$, (variance of VG) and drift of VG, $\theta$.

3.3 Calibration of data for the parameters of the oil process

Calibration of data was done using maximum likelihood estimation process, MLE. Two processes considered are the mean reverting, Ornstein-uhlenbeck (O-U) , process and a subordinated Lévy process, Variance Gamma (VG). Parameter values are obtained for each of the two processes using $\mathrm{R}$ statistical package.

Table 2: OU PARAMETERS

\begin{tabular}{|c|l|l|}
\hline \multicolumn{1}{|l|}{ TYPE } & Mean $\alpha$ & Vol $\sigma$ \\
\hline BL & 71.49338901 & 21.23606388 \\
\hline FB & 70.38885929 & 23.58284355 \\
\hline QL & 53.4152558 & 32.52533274 \\
\hline BB & 71.82665219 & 21.89534891 \\
\hline ESC & 70.31012184 & 23.69099342 \\
\hline PL & 72.20670171 & 22.07915967 \\
\hline ANTAN & 69.44279201 & 22.05442617 \\
\hline YOHO & 68.68628743 & 25.12259855 \\
\hline AME & 68.56037041 & 25.15704196 \\
\hline UKPO & 60.04738667 & 35.10172905 \\
\hline ABO & 60.83765706 & 28.97048242 \\
\hline IME & 59.66053667 & 35.01734336 \\
\hline OKONO & 57.24444831 & 27.25513794 \\
\hline
\end{tabular}

Table 3: Parameters of the VG-model

\begin{tabular}{|c|c|c|c|c|}
\hline Crude Type & Location parameter $\mu$ & $\begin{array}{c}\text { Speed } \\
\text { Parameter } \theta\end{array}$ & $\begin{array}{c}\text { The asymmetry } \\
\text { parameter } \sigma\end{array}$ & $\begin{array}{c}\text { The Shape } \\
\text { Parameter } \nu\end{array}$ \\
\hline BL & 9.0076 & 3.1837 & 56.5214 & 0.1374 \\
\hline FB & 71.320 & $49 . .178$ & -34.817 & 1.833 \\
\hline QL & 5.2540 & 8.8676 & 64.2039 & 0.1184 \\
\hline BB & 181.5583 & 7.0123 & -132.0270 & 0.1184 \\
\hline ESC & 121.4919 & 22.5143 & -53.7653 & 0.1184 \\
\hline PL & -22.8995 & 4.6734 & 93.8197 & 0.1184 \\
\hline ANTAN & 179.0202 & 9.0396 & -133.0744 & 0.1184 \\
\hline YOHO & 44.2191 & 10.9447 & 27.8540 & 0.4389 \\
\hline AME & 139.4743 & 23.7300 & -133.8352 & 0.4821 \\
\hline UKPO & 73.340 & 53.023 & -35.221 & 2.288 \\
\hline ABO & -42.4688 & 5.1721 & 102.5921 & 0.1189 \\
\hline IME & 59.640 & 19.445 & 10.007 & 1.448 \\
\hline OKONO & -64.0324 & 5.7250 & 116.6728 & 0.1184 \\
\hline
\end{tabular}

\subsubsection{On the parameters}

Drift of the Brownian Motion, $\theta$, accounts for the skewness. The variance of time change, $v$, accounts for jumps in the process. It is known as the shape parameter because it relates to kurtosis or peakedness of the process. The spread parameter (which accounts for volatility) are generally single digit for the VG. Lower values of skewness parameter implies there are more of higher prices (than the average). High values of skewness parameter imply there are more of lower prices (than average). There are some crude types whose distributions are left skewed. The others are right skewed. The first three crude types with the highest values of (left) skewness eventually yielded highest $V_{t}$ values.

\subsubsection{Comparing Parameters for Return Series and Price Series}

Parameters obtained for price data here, are far higher than values obtained in krichene's work. In this work 
actual prices are used because actual price $\mathrm{P}_{\mathrm{t}}$ is used in the model formulation. Most financial studies involve returns instead of price for two reasons. For the average investor return on an asset is a complete and scale free summary of investment opportunity. Return series are easier to handle than price series because the former have more attractive statistical properties. Despite the above reasons for preference for returns, prices are used, because there are several varying definitions of asset return. Moreover, an investor in a field project may be more concerned about actual price of crude oil.

\section{Remark:}

Lévy processes are preferred for modeling crude oil price largely to make up for limitations of the BlackScholes model. They are more versatile than the Gaussian driven processes. Lévy processes are proposed to make up for the short-fall of the BlackScholes model, by capturing the notion of stochastic volatility and to model small and frequent jumps.

\subsection{Empirical Crude oil spot price data as a Lévy process}

To show that a price series is a Lévy process, basically it is shown that the price increments (difference series) are stationary and independent. The augmented DickeyFuller (ADF) test is a test for stationarity. The Kolmogorov -Smirnov normality test together with Durbin-Watson autocorrelation test establish independence. The crude oil spot price process has been shown to be Lévy process. [6] Crude oil spot price data for some Niger Delta fields was used.

\section{Model and Analysis of Results \\ 4.1 The model}

It is assumed in the model that trading is done only in the spot market, and the aggregate OPEC quota as used in the model is interpreted to filter down in the micro sense to each field. Also, the expected return on the investment is assumed to depend largely on production and price. The expected value problem is given below:

Let $V_{t}\left(P_{t}, n_{t}, r_{t}\right)$ be the expected return on the project.

$$
V_{t}\left(P_{t}, n_{t}, r_{t}\right)=E\left[\int_{T}^{T} P_{t} e^{r(\tau-T)} n_{t} d t\right]
$$

We want the maximum $V_{t}\left(P_{t}, n_{t}, r_{t}\right)$ subject to constraints on $\mathrm{n}_{\mathrm{t}}$

Thus,

$\mathrm{V}_{\mathrm{t}}=$

$\max _{n_{t}, P_{t}} E\left[\int_{T}^{T} P_{t} e^{r(\tau-T)} n_{t} d t\right]$

$$
n_{t} \leq n_{\max }
$$

Equation (4) defines the expected return on the investment. Suppose initial time is $\mathrm{T}=0$, then,

$$
\mathrm{V}_{\mathrm{t}}=\max _{\mathrm{n}_{\mathrm{t}}, \mathrm{P}_{\mathrm{t}}} \mathrm{E}\left[\int_{0}^{\mathrm{T}} \mathrm{P}_{\mathrm{t}} \mathrm{e}^{\mathrm{r \tau}} \mathrm{n}_{\mathrm{t}} \mathrm{dt}\right]
$$

$\mathrm{P}_{\mathrm{t}}$ is oil price at time $\mathrm{t}$, and is modeled as a stochastic process. ris interest rate, $n_{t}$ is number of barrels produced and sold at time $t$ which is regulated. (A barrel of oil is 42 gallons or 159 litres). $\tau$ is the break through time. $\mathrm{T}$ is time when production started. We set $\mathrm{T}=0$. $\mathrm{e}^{\mathrm{r \tau}}$ is the discount factor.

Given information on price $\mathrm{P}_{\mathrm{t}}, \mathrm{n}_{\mathrm{t}}$ is a bounded quantity and is related to price $P_{t}$

$$
\mathrm{n}_{\mathrm{t}}=\prod\left(\mathrm{P}_{\mathrm{t}}\right)
$$

$n_{t}$ is measurable with respect to $P_{t}, n_{t}$ is adapted to $\mathrm{P}_{t}, \mathrm{n}_{\mathrm{t}}$ is considered a filtration generated by $\mathrm{P}_{t}$. The relationship between $n_{t}$ and $P_{t}$ is defined by

$\mathrm{n}_{\mathrm{t}}=\frac{\mathrm{CP}_{\mathrm{t}}^{\alpha}}{\mathrm{P}_{\mathrm{t}}^{\alpha}+1}$

$\mathrm{C}=$

$\mathrm{n}_{\max }$

Equation (5) defines the relationship between $n_{t}$ and $\mathrm{P}_{\mathrm{t}}$ with respect to OPEC quota. $\mathrm{C}$ is maximum quantity that can be produced. $\alpha$ is the bound regulator which controls the speed at which the upper bound is attained. The actual bound on $n_{t}$ i.e. $n_{t} \leq n_{\text {max }}$ is determined by some technical constraints along with the OPEC regulatory constraints. We assume optimality for other factors.

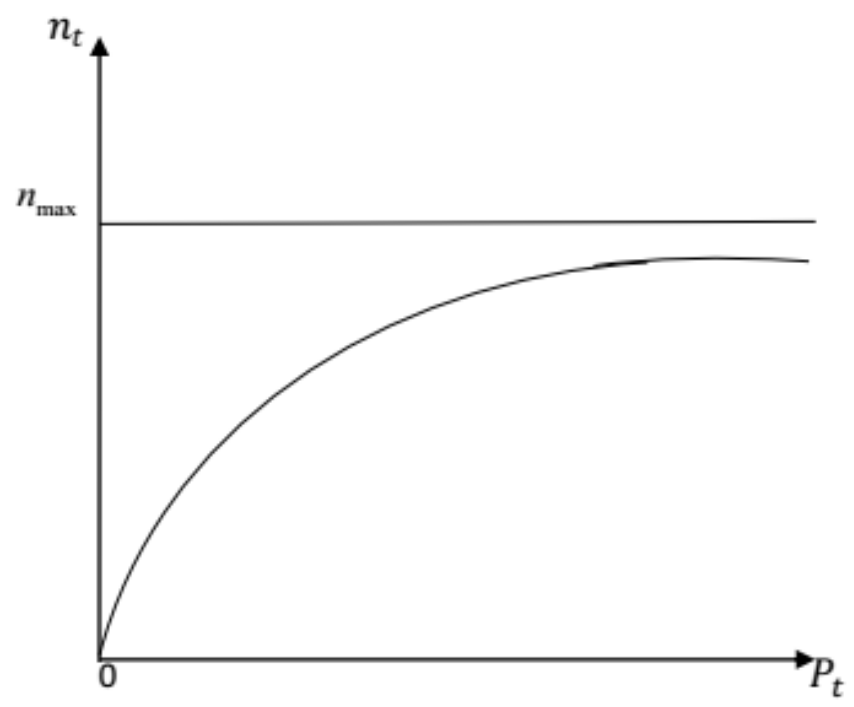

Figure 1: Illustration of Bound on quantity produced 
Table 4: Lending I-rate and Deposit I- rate Nigeria 2005-2009

\begin{tabular}{|c|c|c|c|c|c|}
\hline Year & $\mathbf{2 0 0 5}$ & $\mathbf{2 0 0 6}$ & $\mathbf{2 0 0 7}$ & $\mathbf{2 0 0 8}$ & $\mathbf{2 0 0 9}$ \\
\hline Deposit Rate & 10.53 & 9.74 & 10.29 & 11.29 & 13.3 \\
\hline Lending Rate & 17.95 & 16.9 & 16.94 & 15.48 & 18.36 \\
\hline
\end{tabular}

Source: Lending I-rate and Deposit I-rate Nigeria 2005-2009 http://www.tradingeconomics.com/nigeria/lending-rateprecent-wb-data.html and CBN Bulletins, 2006, 2007, 2008, 2009. Average of deposit rate and lending rate is used in the model.

\subsection{The Computational program}

The objective: is to obtain optimal expected return on investment for each price process, O-U and VG. The price processes are generated using their various parameters as displayed on Tables [2] [3]. Computations for optimal expected return, (on investment) were done using a program written with PYTHON. The start position for the simulation is price for each crude type as at January 2005. An alpha value of 0.5 was selected for the program because the system achieved equilibrium better for alpha equal to 0.5 . (from initial simulation results). For $\mathrm{n}_{\max }=5$ million, a time period of 60 months the following was done. Each time, the process $\mathrm{P}_{\mathrm{t}}$ is generated for each process, using the estimated parameters on Tables [2] [3].The OPEC constraint was taken into consideration, i.e. for each set of values generated, $\quad \mathrm{n}_{\mathrm{t}}=\frac{\mathrm{CP}_{\mathrm{t}}^{\alpha}}{\mathrm{P}_{\mathrm{t}}^{\alpha}+1}$ was obtained, $\mathrm{n}_{\mathrm{t}}$, was applied on each $\mathrm{P}_{\mathrm{t}}$ generated process. Several integral values for these products were obtained. The mean of these set of integral values, is the expected value $V_{t}$.

\subsection{Expected Returns $V_{t}$ for each process}

The values of $V_{t}$ obtained from the program for each process for $\alpha=0.5$ are displayed on the following tables. [5] and [6]

\begin{tabular}{|c|c|c|}
\hline FIELD & CRUDE TYPE & $\mathbf{V}_{\mathbf{t}}(\mathbf{U S D})$ \\
\hline Inda & $\mathrm{BL}$ & $23,437,045.15$ \\
\hline Ughelli East & $\mathrm{FB}$ & $24,602,995.74$ \\
\hline USari & QL & $22,853,370.99$ \\
\hline Jisike & BB & $23,213,462.11$ \\
\hline Meren & ESC & $22,686,595.70$ \\
\hline Funiwa & PL & $24,430,838.24$ \\
\hline Noron & Antan & $24,682,512.15$ \\
\hline Yoho & Yoho & $25,188,623.38$ \\
\hline Amenam & Ame & $23,432,838.51$ \\
\hline Ukpokiti & Ukpo & $25,188,179.40$ \\
\hline Abo & Abo & $23,252,820.80$ \\
\hline Ngo & Ima & $25,242,415.60$ \\
\hline Okono/Okpoho & Okono & $21,809,242.31$ \\
\hline
\end{tabular}

Table 5: $V_{t}$ VALUES FOR O-U PROCESS $\alpha=0.5$ Lowest $V_{t}$ Value $=21,809,242.31$

Highest $V_{t}$ Value $=25242,415.60(\mathrm{Ima})$

Lowest $V_{t}$ Value $=21,809,242.31$ (Okono)

Table 6: $\mathrm{V}_{\mathrm{t}}$ VALUES FOR VG PROCESS $\alpha=0.5$

\begin{tabular}{|l|l|l|}
\hline FIELD & CRUDE TYPE & $\mathbf{V}_{\mathbf{t}}$ (USD) \\
\hline Inda & BL & $570,823,546.47$ \\
\hline Ughelli East & FB & $193,334,997.71$ \\
\hline Usari & QL & $690,651,072.43$ \\
\hline Jisike & BB & $1,416,029,327.64$ \\
\hline Meren & ESC & $591,572,829.02$ \\
\hline Funiwa & PL & $964,004,252.92$ \\
\hline Noron & Antan & $1,423,038,808.46$ \\
\hline Yoho & Yoho & $295,404,198.65$ \\
\hline Amenam & Ame & $1,506,0999,994.00$ \\
\hline Ukpokiti & Ukpo & $328,576,402.93$ \\
\hline Abo & Abo & $1,027,559,313.32$ \\
\hline Ngo & Ima & $160,498,726.65$ \\
\hline Okono/Okpoho & Okono & $1,221,572,908.25$ \\
\hline
\end{tabular}


4.4 Analysis

Highest $V_{t}$ value $=1,506,099,994.00($ Ame $)$ : Lowest

$V_{t}$ value $=160,498,726.65(I m a)$

\subsection{Analysis of Results}

\subsubsection{Ornstein-Uhlenbeck Process}

The O-U process has only two parameters, Mean and Volatility. There is not much difference in volatility values for various crude types. This accounts for the small difference in $\mathrm{V}_{\mathrm{t}}$ values for various fields. The $\mathrm{O}-\mathrm{U}$ process yields less values of $V_{t}$, when compared with VG processes. Volatility is the only parameter accounted for in the price movement. Not very good results are expected with the $\mathrm{O}-\mathrm{U}$ process. The $\mathrm{O}-\mathrm{U}$ process usually generates both positive and negative values (oil prices) over time. This can be seen on graph in Fig 2. Therefore, considering the price process as a mean reverting $(\mathrm{O}-\mathrm{U})$ process will lead to Sub-optimal results on investments and incorrect calculation of expected returns.

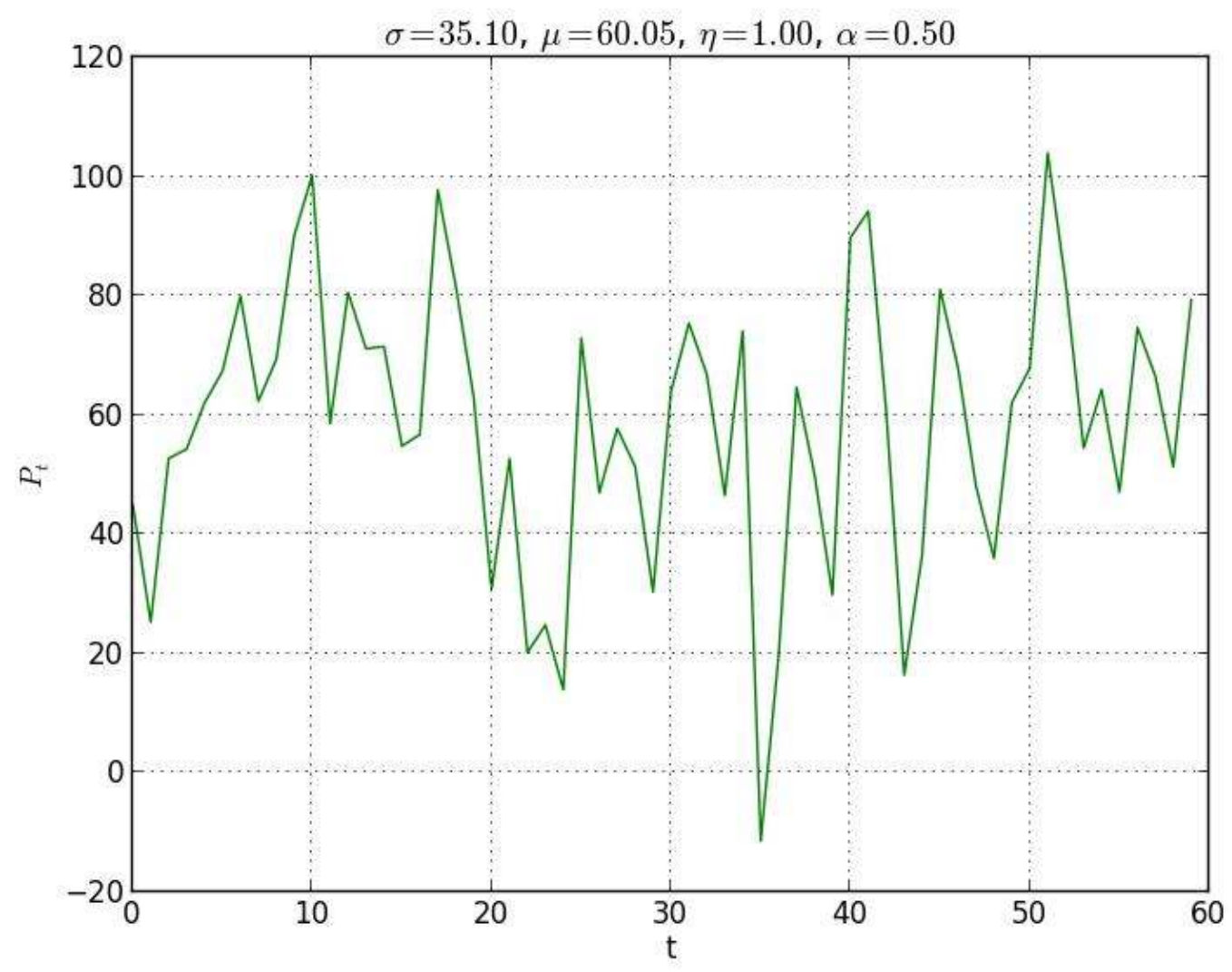

Figure 2: UKPO: O-U PRICE-TIME GRAPH

\subsubsection{The Variance Gamma Process}

$V_{t}$ values, for the VG process are generally higher than $V_{t}$ values for the $\mathrm{O}-U$ process. For the $V G$ process, comparatively low values of volatility, together with high drift (of $B M$ ) values, yielded higher $V_{t}$ values. The trend is broken only when volatility and drift (of BM) are very low and very high respectively. Fields with higher vvalues yielded less $V_{t}$,values. Crude types with most skewed (left) price distribution yielded the highest $\mathrm{V}_{\mathrm{t}}$ value. This is in consonance with krichene's work. Findings from his work, shows that VG process is left skewed. 


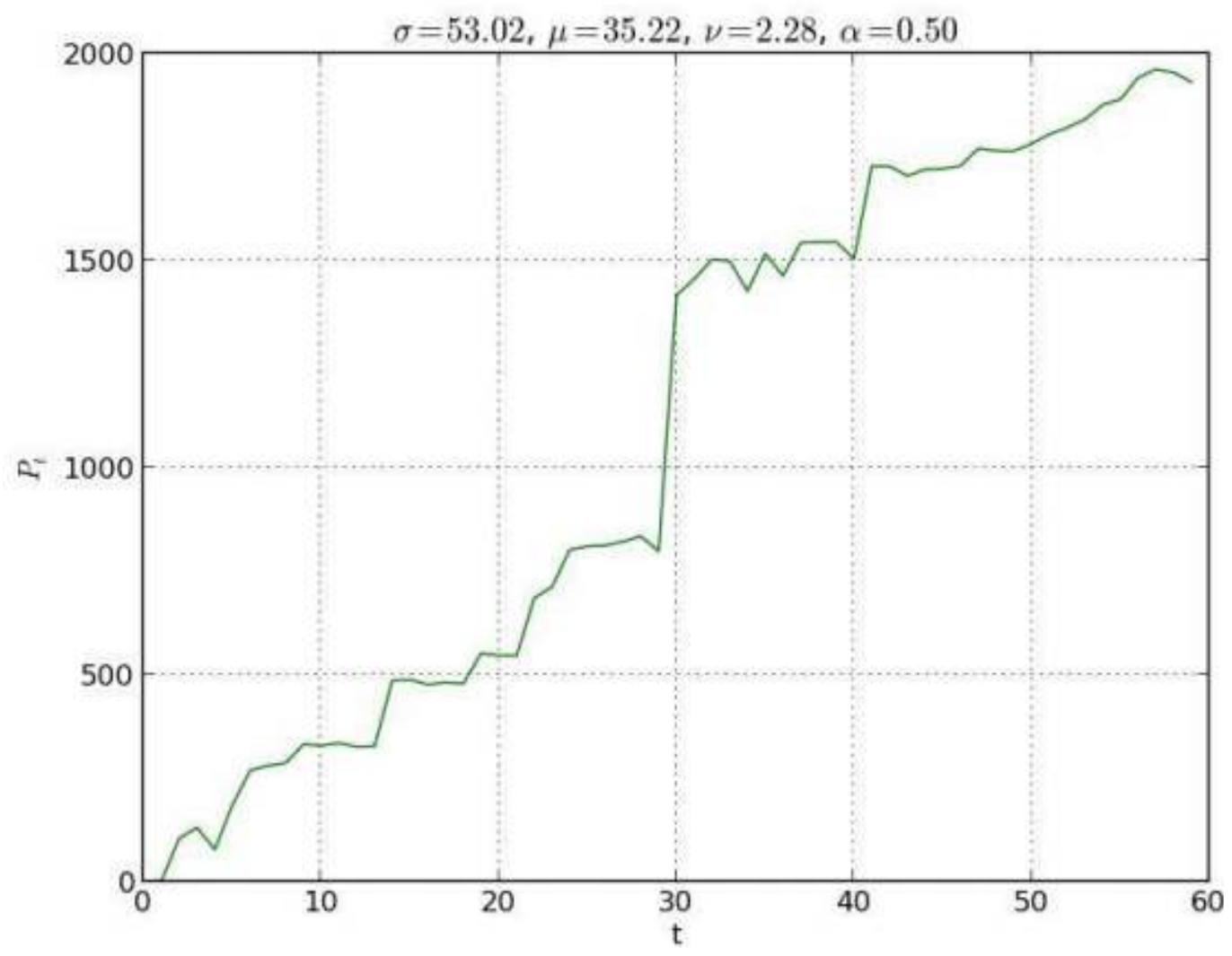

Figure 3: UKPO: VG PRICE-TIME GRAPH

\section{CONCLUSION}

From the model (which includes production constraints), expected revenue are higher for the subordinated Levy process than for the Ornstein Uhlenbeck process. This is an indication of better performance for the Variance Gamma process as the process describing the crude oil price. The contribution of drift and volatility parameter values in the analysis is important in terms of explaining fluctuations and jumps in the price process. Despite the fact that gaps in the data may be responsible for the type of parameters obtained for some crude types. The VG process is considered a better price model for the data. The missing data could be accounted for by crises that were prevalent in the Niger Delta region during the period under study.

\section{ACKNOWLEDGEMENT}

I wish to thank DPR, COMD, NAPIMS, Lagos, for supplying the Data used, IMSP Porto-Novo for hosting me on a research visit, AMMSI for a postgraduate scholarship award. Many thanks too to Richard Lartey and Richard Minka for their assistance in processing the data.

\section{REMARK:}

Appendix includes:- CRUDE OIL PRICES 2005 - 2009 , R- CODE FOR PARAMETER ESTIMATION FOR VG AND O-U PROCESSES, PYHON CODE IMPLEMENTED FOR VG PROCESS,AND PYTHON CODE IMPLEMENTED FOR O-U PROCESS.
Author can be contacted for data and codes.

\section{REFERENCES}

Adelman M.A., "Crude oil supply curve". International Association for Energy Economics Vol 7, issue 4-October 1986. (Revision of MIT Laboratory Working paper). www.iaee.org/documents/vol7(4)

Coding Algorithm for Stochastic Processes using PYTHON.pyprocess.70percentfatfree.com

Daniel T. Gillespie "Exact numerical simulation of the Ornstein-Uhlenbeck process and its integral" Phys. Rev. E 54, 2084 Published 1 August 1996.

David Scott and Christine Yan Dong, "Package Variance Gamma version, 0.3 1" Http//www.r-project.org. April 13. 2012.

Krichene Noureddine, "Recent Dynamics of Crude Oil Prices" IMF Working Paper. WP/06/299. http://wwww.imf.org. 2006

Noureddine Krichene. Crude Oil Prices: Trends and Forecasts. IMF working paper. WP/08/133. https://www.imf.org/external/pubs/ft/wp/2008/wp 08133. 2008

Ogbogbo Chisara P. "The crude oil spot price process is a Lévy process" Journal of the Nigerian 
Association of Mathematical Physics. Vol 42. NO 1. 2017

Roger J-B. Wells and Ignacio Rios," Modeling and Estimating Commodity Prices: Copper Prices. https://www.math.ucdavis.edu/rib/mypage/Mathematics. 2012.

Ruey S. Tsay" Analysis of Financial Time Series" 2nd Edition. Wiley and Sons Inc. 2005

Schwartz E. S. "The Stochastic behavior of commodity Prices: Implications for valuation and Hedging".
The Journal of Finance 52 (3) pp. 923-973. 1997.

William Smith. "On the Simulation and Estimation of the Mean-Reverting Ornstein Uhlenbeck Process: Especially as Applied to Commodities Markets and Modeling." Commodity Models, 2010. http://commodity models.les. word press. com/2010/02/estimating-the- parameters-of-amean-reverting-ornstein-uhlenbeckprocess1.pdf. Checked December 2016. 